\title{
Enhanced visible light catalytic activity of MoS2/TiO2/Ti photocathode by hybrid- junction
}

Cheng, Chaoqun; Liu, Guohua; Du, Kang; Li, Gang; Zhang, Wendong; Sanna, Simone; Chen, Yunzhong; Pryds, Nini; Wang, Kaiying

Published in:

Applied Catalysis B: Environmental

Link to article, DOI:

10.1016/j.apcatb.2018.06.012

Publication date:

2018

Document Version

Peer reviewed version

Link back to DTU Orbit

Citation $(A P A)$ :

Cheng, C., Liu, G., Du, K., Li, G., Zhang, W., Sanna, S., Chen, Y., Pryds, N., \& Wang, K. (2018). Enhanced visible light catalytic activity of MoS2/TiO2/Ti photocathode by hybrid-junction. Applied Catalysis $B$ :

Environmental, 237, 416-423. https://doi.org/10.1016/j.apcatb.2018.06.012

\section{General rights}

Copyright and moral rights for the publications made accessible in the public portal are retained by the authors and/or other copyright owners and it is a condition of accessing publications that users recognise and abide by the legal requirements associated with these rights.

- Users may download and print one copy of any publication from the public portal for the purpose of private study or research.

- You may not further distribute the material or use it for any profit-making activity or commercial gain

- You may freely distribute the URL identifying the publication in the public portal 


\section{Accepted Manuscript}

Title: Enhanced visible light catalytic activity of $\mathrm{MoS}_{2} / \mathrm{TiO}_{2} / \mathrm{Ti}$ photocathode by hybrid-junction

Authors: Chaoqun Cheng, Guohua Liu, Kang Du, Gang Li, Wendong Zhang, Simone Sanna, Yunzhong Chen, Nini Pryds, Kaiying Wang

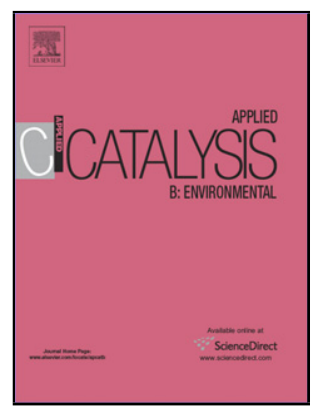

PII: S0926-3373(18)30538-1

DOI:

Reference: https://doi.org/10.1016/j.apcatb.2018.06.012

To appear in: APCATB 16760

Received date:

Applied Catalysis B: Environmental

Revised date:

$15-4-2018$

Accepted date:

$31-5-2018$

3-6-2018

Please cite this article as: Cheng C, Liu G, Du K, Li G, Zhang W, Sanna S, Chen Y, Pryds N, Wang K, Enhanced visible light catalytic activity of $\mathrm{MoS}_{2} / \mathrm{TiO}_{2} / \mathrm{Ti}$ photocathode by hybrid-junction, Applied Catalysis B: Environmental (2018), https://doi.org/10.1016/j.apcatb.2018.06.012

This is a PDF file of an unedited manuscript that has been accepted for publication. As a service to our customers we are providing this early version of the manuscript. The manuscript will undergo copyediting, typesetting, and review of the resulting proof before it is published in its final form. Please note that during the production process errors may be discovered which could affect the content, and all legal disclaimers that apply to the journal pertain. 


\section{Enhanced visible light catalytic activity of $\mathrm{MoS}_{2} / \mathrm{TiO}_{2} / \mathrm{Ti}$ photocathode by hybrid-junction}

Chaoqun Cheng ${ }^{\mathrm{a}}$, Guohua Liu ${ }^{\mathrm{b}}$, Kang Du ${ }^{\mathrm{a}}$, Gang Li ${ }^{\mathrm{c}}$, Wendong Zhang ${ }^{\mathrm{c}}$, Simone Sanna ${ }^{\mathrm{d}}$, Yunzhong Chen $^{\mathrm{d}}$, Nini Pryds ${ }^{\mathrm{d}}$ and Kaiying Wang ${ }^{\mathrm{a}, *}$

a Department of MicroSystems, University College of Southeast Norway, Horten 3184, Norway

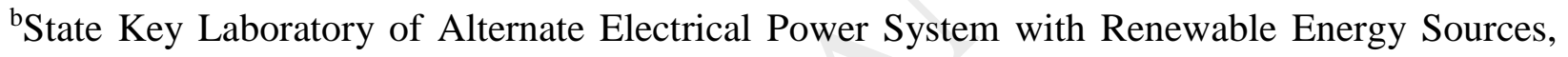
North China Electric Power University, Beijing 102206, China

${ }^{\mathrm{c}}$ Micro and Nano System Research Center, Key Lab of Advanced Transducers and Intelligent Control System (Ministry of Education) \& College of Information Engineering, Taiyuan University of Technology, Taiyuan, 030024, China.

${ }^{\mathrm{d}}$ Department of energy conversion and storage, Technical University of Denmark, Ris $\emptyset$ Campus, 4000 Roskilde, Denmark

\section{Corresponding Author}

*E-mail: Kaiying.Wang@usn.no 


\title{
Graphical Abstract
}

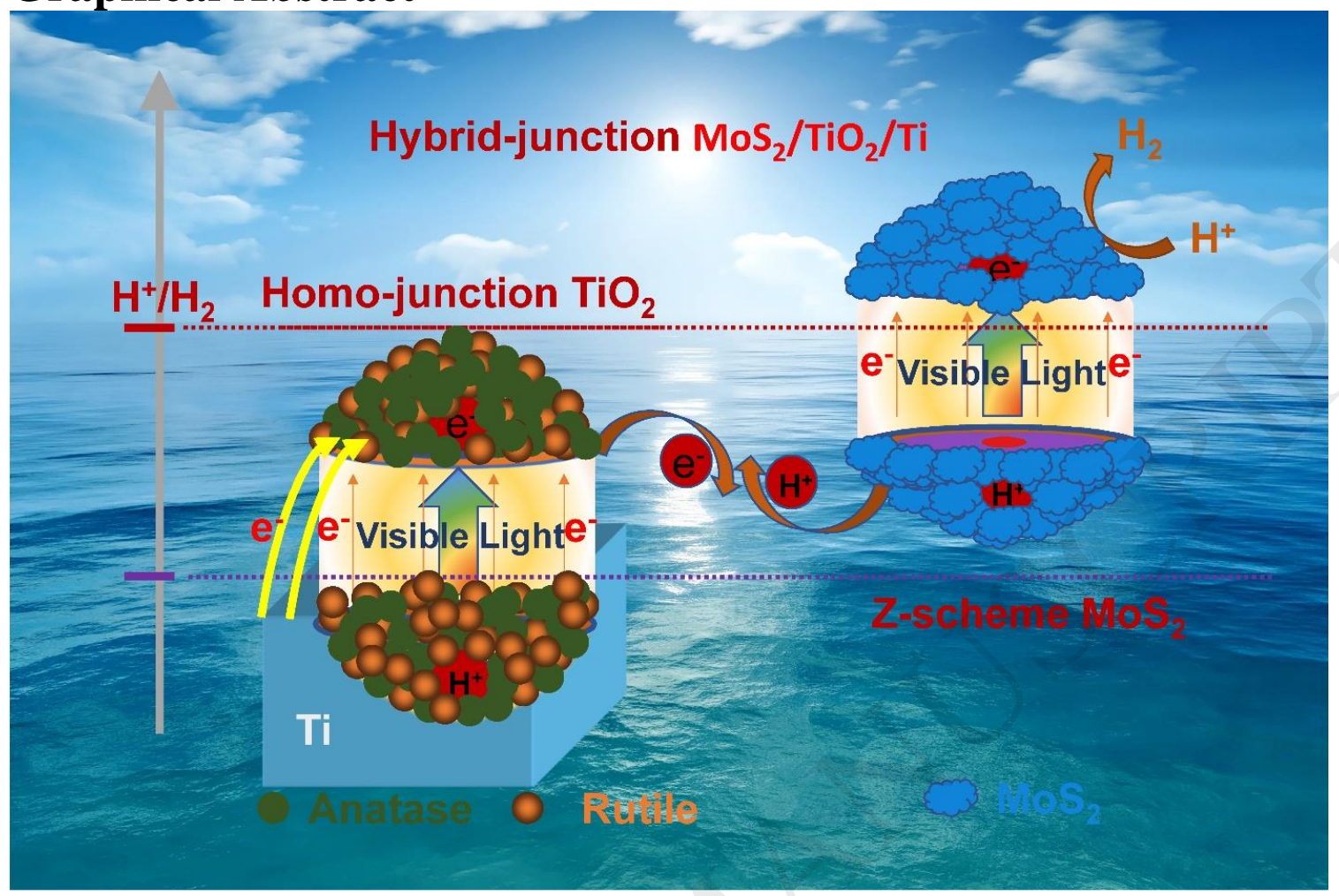

\section{Highlights}

- $\mathrm{MoS}_{2} / \mathrm{TiO}_{2} / \mathrm{Ti}$ photocathode was facile fabricated with visible light responsivity.

- Enhanced catalytic activity under visible light illumination was achieved.

- The enhancement was due to improved charge separation, transfer and transport.

- A proper charge-carrier dynamics of hybrid-junction was proposed.

\begin{abstract}
:
In photoelectrochemical (PEC) water splitting systems, crucial obstacles limiting their performance are poor charge carrier dynamics and high recombination rate of photoexcited electron hole pairs. Here, we report that this issue can be alleviated by engineering a hybridjunction that is composed of homo- and hetero- junctions. This strategy is performed by facile hand-spraying $\mathrm{MoS}_{2}$ over the surface of a anatase/rutile homo-junction $\mathrm{TiO}_{2}$ film on the $\mathrm{Ti}$
\end{abstract}


substrate to further form a hybrid-junction photocathode. By applying this photocathode into PEC reactor, enhanced catalytic activity is achieved under visible light (AM1.5 illumination of 300 $\mathrm{W} / \mathrm{m}^{2}$ ) with hydrogen evolution reaction (HER) potential of $-114 \mathrm{mV}$ versus reversible hydrogen electrode (RHE) at $10 \mathrm{~mA} / \mathrm{cm}^{2}$ and long-term stability of more than 10 times improvement comparing to ordinary electrode without the introduciton of hybrid-junction. The hybrid-junction that effectively regulates charge separation and transfer pathways is proven to be responsible for the enhanced activity. As an novel exploration, this hybrid-junction system comprising of lowcost, efficient charge separation and transfer, and visible light responsivity offers a new path for relative materials to boost their PEC performance.

\section{KEYWORDS:}

hybrid-junction, water splitting, titanium dioxide, Z-scheme, molybdenum disulfide

\section{Introduction}

Photoelectrochemical (PEC) water splitting system harvesting sunlight to drive uphill water splitting reactions has been the focus of attention due to its potential of converting sunlight into chemical fuels in a cost-economical and sustainable way ${ }^{[1-4]}$. In the past decades excellent advancement has been achieved, specially the metal oxide semiconductor has been invested greatly due to their intrinsic nature of the d orbital states, earth-abundance and superior PEC performance ${ }^{[5-8]}$. However, their PEC performance to the practical commercialization is still subjected to the limitations of poor charge-carrier dynamics and high recombination rate issues under the solar illumination $^{[9,10]}$. To solve these issues, some efforts have been made to pursue reliable strategies in particular the search for hybrid systems ${ }^{[3,11-13]}$. 
Hetero- and homo-junctions are two distinctive approaches used in the hybrid systems ${ }^{[14,15]}$. The designing of hetero-junction is a well-established approach as it holds great potential to overcome the drawbacks of serious charge recombination and limited visible-light utilization ${ }^{[16]}$, typically involving building an advanced two-step (Z-scheme) system. The Z-scheme system composed of two semiconductors with desired band gaps and energy positions ensure that the separated electrons and holes transport only in opposite directions toward surface for preferred reactions, minimizing deleterious recombination and undesirable side reactions ${ }^{[17,18]}$. Z-scheme construction can not only regulate charge transfer pathways but also increase the sunlight utilization through the series connected two semiconducting materials with narrow bandgap absorbing visible light ${ }^{[19,20]}$. As an example, there have been reports that Z-scheme hetero-junction of $\mathrm{MoS}_{2} / \mathrm{TiO}_{2}$ with CdS quantum dots can effectively improve the catalytic activities under the visible light irradiation as the result of beneficial charge interaction in the interface ${ }^{[21]}$. Recent studies have also demonstrated that the excellent catalytic activity in the heterojunctions of $\mathrm{MoS}_{2} / \mathrm{TiO}_{2}$ is related to the strong interaction between the $\mathrm{MoS}_{2}$ and $\mathrm{TiO}_{2}{ }^{[22-27]}$.

On the other hand, the construction of homo-junction (phase-junction) is an alternative configuration access to charge separation because the formation of homo-junction between two distinct phases can adjust the transport of the charge carriers along the inter-phases band alignment [9]. For example, it has been reported that surficial phase-junction between the nanoparticles of anatase and rutile $\mathrm{TiO}_{2}$ can enhance the water splitting activities ${ }^{[28]}$. The basic mechanism is that the surficial anatase/rutile phase junctions can guide the electrons or holes transferred between band structures of rutile and anatase $\mathrm{TiO}_{2}$, thereby facilitating separation of electron-hole pairs and catalytic activities ${ }^{[28-30]}$. 
Although configuring hetero-junction or homo-junction is well explored, the potentials of integrating hybrid-junction comprising of hetero-junction and homo-junction into a single photoelectrode is still lack of investigation, especially in terms of the impact on charge carrier dynamics. In the heterogeneous system, the doping of foreign elements ${ }^{[31-33]}$ was explored to provide multi-channel paths for improving the charge-carrier dynamics. In this study, we propose a facile strategy of building hybrid-junction to improve the catalytic activity of photocathode under visible light. We demonstrate that integration of homo-junction and hetero-junction on the bulk metal substrate as a simple but effective strategy could effectively fast the performance of charge separation, transfer and transportation dynamics at the interface and reduce charge carrier recombination in the bulk and at the surface.

We fabricated hybrid-junction of $\mathrm{MoS}_{2} / \mathrm{TiO}_{2}$ by hetero-coupling $\mathrm{MoS}_{2}$ and homo-junction (mixed-phases) $\mathrm{TiO}_{2}$ on the substrate of $\mathrm{Ti}$ foil. The hybrid-junction $\mathrm{MoS}_{2} / \mathrm{TiO}_{2}$ exhibits high activities under a visible light irradiation (AM $1.5 \mathrm{G}$ illumination of $300 \mathrm{~W} / \mathrm{m}^{2}$ ) with hydrogen evolution reaction (HER) potential of $-114 \mathrm{mV}$ versus reversible hydrogen electrode (RHE) at 10 $\mathrm{mA} / \mathrm{cm}^{2}$, as well as long-term stability for more than 12 hours at $-0.3 \mathrm{~V}$ vs RHE while comparing to about 1 hour without the introduction of hybrid-junction under same measurement conditions, more than 10 times improvement. The homo-junction $\mathrm{TiO}_{2}$ thin layer on the substrate of $\mathrm{Ti}$ was synthesized through simple one-step thermal annealing process, different from traditional synthesis using hydrothermal or sol-gel methods ${ }^{[34-36]}$. The characterization on the HER activities suggest the homo-junction $\mathrm{TiO}_{2}$ on the substrate of $\mathrm{Ti}$ could facilitate charge separation and transportation under the visible light illumination. After the hetero-coupling with $\mathrm{MoS}_{2}$ constructed as hybrid-junction system, this cathode composite of $\mathrm{MoS}_{2} / \mathrm{TiO}_{2}$ on the substrate $\mathrm{Ti}$ exhibit higher activity and stability during the HER. The underlying charge transfer analysis 
elucidated that the hybrid-junction of Z-scheme hetero-junction and homo-junction plays important roles in the excellent performance.

\section{Experimental section}

\subsection{Materials}

Commercially Molybdenum disulfide $\left(\mathrm{MoS}_{2}\right)$ microflakes liquid-spraying was purchased from CRC Industries Americas Group. Titanium foils (Ti foils, $30 \mathrm{~mm} \times 14 \mathrm{~mm} \times 0.5 \mathrm{~mm}, 99.8 \%$ purity) were cut out from Ti sheet, which was purchased from Baoji Titanium Industry Co., LTD. Ethanol, acetone, isopropanol and deionized water were obtained from Sigma-Aldrich without further purification.

\subsection{Preparation of homo-junction $\mathrm{TiO}_{2}$ and $\mathrm{MoS}_{2} / \mathrm{TiO}_{2}$ composite electrodes}

The fabrication consists of oxidation, spraying and annealing processes. Initially, Ti foils were cleaned by immersing the foils into the acetone rinsed by ultrasonic bath and subsequently dried in flowing nitrogen gas. After the initial cleaning step, Ti foils were oxidized at 400,500 and $600{ }^{\circ} \mathrm{C}$ for 2 hours with oxygen gas continually flowing through the quartz tube furnace to generate a thin layer of homo-junction $\mathrm{TiO}_{2}$ on the surface of the Ti foil (Figure S1). Following the oxidation step, commercial lubricating $\mathrm{MoS}_{2}$ spray (CRC Industries) was applied to the $\mathrm{TiO}_{2} / \mathrm{Ti}$, followed by baking at $100{ }^{\circ} \mathrm{C}$ in the oven with ambient atmosphere for 10 hours to ensure that all the solvent is evaporated. In the last annealing process, the pristine $\mathrm{MoS}_{2} / \mathrm{TiO}_{2} / \mathrm{Ti}$ foils were annealed at $500{ }^{\circ} \mathrm{C}$ for 1, 2, and 3 hours, respectively in Nitrogen atmosphere under ambient pressure and cooled to the room temperature.

\subsection{Physical Characterization}

Surface morphology of as-prepared samples was examined by field emission scanning electron microscopy (FESEM) (Hitachi, SU 8230) equipped with energy-dispersive X-ray spectrum (EDS) 
and electron backscatter diffraction (EBSD) microstructural-crystallographic characterization. Atomic force microscopy (AFM, Parker XE 200) was used to visualize surface the topography of samples on the nanometer scale. UV-Vis light absorption spectra of the as-prepared samples were obtained using a SHIMADZU, UV-2600 spectrophotometer equipped with an integrated sphere assembly using diffuse reflection method. $\mathrm{BaSO}_{4}$ was used as a reference to measure all samples in the wavelength range of $250-800 \mathrm{~nm}$ with a slit width of $1 \mathrm{~nm}$. X-ray diffraction (XRD) patterns were collected on a Bruker D8-Advance diffractometer using $\mathrm{Cu} K \alpha$ radiation $(\lambda=1.5405 \AA)$ in a range of $2-80^{\circ}$ at a scan rate of $5^{\circ} / \mathrm{min}$. Photoluminescence (PL) spectra were performed in the FS5 Spectrofluorometer of Edinburgh Instruments by focusing the laser radiation centered at 400 nm from an Xeon lamp onto the samples.

\subsection{Photoelectrochemical Measurement}

PEC/Electrochemical measurements with/without simulated solar light illumination were performed and evaluated in a standard PEC three electrodes setup which is connected to electrochemical workstation (Zahner Elektrik IM6). The incident light was filtered through AM $1.5 \mathrm{G}$ solar simulator over an adjustable $500 \mathrm{~W}$ Xeon lamp (AM 1.5G, $\left.300 \mathrm{~W} / \mathrm{m}^{2}\right)$. The as-prepared composites, platinum gauze and $\mathrm{Ag} / \mathrm{AgCl}$ with saturated $\mathrm{KCl}$ solution were used as working, counter and reference electrodes. In the text, the measured potentials $v s . \mathrm{Ag} / \mathrm{AgCl}$ were all changed to the RHE scale based on the Nernst equation: $\boldsymbol{E}_{\mathrm{RHE}}=\boldsymbol{E}_{\mathrm{Ag}} / \boldsymbol{E}_{\mathrm{AgCl}}+\mathrm{pH} * 0.059+0.1976$. All the current density reported in the work were calibrated using IR compensation, where the $\mathrm{R}$ (resistivity) was estimated by electrochemical impedance spectroscopy (EIS) with a frequency ranging from $10 \mathrm{~Hz}$ to $1 \mathrm{M} \mathrm{Hz}$.

Linear scanning voltammetry measurements were carried out in $0.5 \mathrm{M} \mathrm{H}_{2} \mathrm{SO}_{4}$ at a constant scan rate of $20 \mathrm{mV} / \mathrm{s}$ over the potential range of $-0.6-0 \mathrm{~V}$ (vs RHE). A long-term stability test for 
$\mathrm{MoS}_{2} / \mathrm{TiO}_{2}$ and $\mathrm{MoS}_{2} / \mathrm{Ti}$ were conducted by an extended electrolysis (15 hours) under dark or light conditions at a constant reduction potential of $-0.3 \mathrm{~V}$ vs RHE. EIS test were carried out at opencircuit potential by applying an $\mathrm{AC}$ potential with amplitude of $50 \mathrm{mV}$ during the frequency range of $4 \times 10^{5}$ to $10^{-3} \mathrm{~Hz}$ in $0.5 \mathrm{M} \mathrm{H}_{2} \mathrm{SO}_{4}$ with/without the $\mathrm{AM} 1.5 \mathrm{G}$ illumination $\left(300 \mathrm{~W} / \mathrm{m}^{2}\right)$. MottSchottky plots were obtained at frequencies of 5,10 and $15 \mathrm{kHz}$ and amplitude of $10 \mathrm{mV}$ in $0.5 \mathrm{M}$ $\mathrm{H}_{2} \mathrm{SO}_{4}$ solution under the dark or light conditions. In addition, current density-voltage (J-V) characteristic in an anodic direction was acquired at a scan rate of $20 \mathrm{mV} / \mathrm{s}$. The measurements were carried out in a solution of $\mathrm{Na}_{2} \mathrm{SO}_{4}(\mathrm{pH}$ 6.8) and subsequently in another solution of $1 \mathrm{M}$ $\mathrm{KOH}(\mathrm{pH} 13)$.

\section{Results and discussion}

\subsection{Homo-junction $\mathrm{TiO}_{2}$ on the substrate of $\mathrm{Ti}$}

Homo-junction $\mathrm{TiO}_{2}$ was synthesized on the surface of Ti foil using simple one-step annealing process, as presented in the experimental section. The presence of homo-junction (mixed-phases) $\mathrm{TiO}_{2}$ on the surface of $\mathrm{Ti}$ foil after the annealing process was determined by X-ray diffraction (XRD) and electron backscatter diffraction (EBSD). Figure 1a shows the $\mathrm{XRD}$ patterns of $\mathrm{TiO}_{2}$ at temperature ranging from $400{ }^{\circ} \mathrm{C}$ to $600{ }^{\circ} \mathrm{C}$, in which both anatase or rutile $\mathrm{TiO}_{2}$ could be observed (Figure S2). Figure 1b presents the EBSD mapping, clearly showing the mixed-phases orientation mapping on the surface with assorted colors.

Figure 1c shows the UV-Vis absorption spectra, indicating a strong resonant visible light absorption peak around $480 \mathrm{~nm}$ at $500{ }^{\circ} \mathrm{C}^{[37-40]}$. Figure $1 \mathrm{~d}$ further shows the UV-vis absorption spectra, in which the absorption edge wavelength of material moves to the infrared light area in the direction of longer wavelength as the processing temperature increases gradually, confirming the dependence of resonance absorption wavelength on the microscopic changes of surficial 
mixed-phases $\mathrm{TiO}_{2}$ induced by the elevated thermal treatment in the temperature range (Figure S4) [37, 41].

Figure 2 show $J-V$ plots of proton reduction with/without AM 1.5G illumination and corresponding Tafel slope values. Figures $2 \mathrm{a}-\mathrm{c}$ show $J$ - $V$ curves measured in dark and light respectively. As seen from these figures, $\mathrm{TiO}_{2} / \mathrm{Ti}\left(400{ }^{\circ} \mathrm{C}\right)$ and $\mathrm{TiO}_{2} / \mathrm{Ti}\left(500{ }^{\circ} \mathrm{C}\right)$ exhibit better reduction activities under the light condition, while $\mathrm{TiO}_{2} / \mathrm{Ti}\left(600^{\circ} \mathrm{C}\right)$ itself shows a poor reduction current under light, even worse than that in dark. This difference is consistent with the differential absorption spectra in the Figure 1c. For the $\mathrm{TiO}_{2} / \mathrm{Ti}\left(500^{\circ} \mathrm{C}\right)$, an overpotential of $216 \mathrm{mV}$ at 10 $\mathrm{mV} / \mathrm{cm}^{2}$ was achieved under the application of light, almost $50 \%$ improvement comparing to the $403 \mathrm{mV}$ under the dark condition, suggesting that $\mathrm{TiO}_{2} / \mathrm{Ti}(500)$ has better PEC activities in the visible light range. Figure $2 \mathrm{~d}$ presents the Tafel slope for the $\mathrm{TiO}_{2} / \mathrm{Ti}$ under the dark and light, in which the $\mathrm{TiO}_{2} / \mathrm{Ti}\left(50{ }^{\circ} \mathrm{C}\right)$ has a lower Tafel slope value of $159 \mathrm{mV} / \mathrm{decade}$, and thus was better activity than the others. Since the Tafel slope value is close to the Volmer reaction regime (120 $\mathrm{mV} /$ decade $)^{[42,43]}$, the rate-limiting step here is the electrochemical adsorption step due to a limited amount of surface active sites.

\subsection{Hybrid-junction $\mathrm{MoS}_{2} / \mathrm{TiO}_{2} / \mathrm{Ti}$ electrode}

The investigation suggests that the homo-junction $\mathrm{TiO}_{2}$ on the substrate of $\mathrm{Ti}$ has favourable charge transfer features under the visible light illumination but is restricted by the deficient surface sites which could increase the rate of interfacial charge transport. To eliminate the deficit, the homo-junction $\mathrm{TiO}_{2}$ was covered by hand-spraying thin layer of commercial $\mathrm{MoS}_{2}$, forming a functional complementary hetero-junction system. In addition to the merits of containing no precious metals and earth abundance, $\mathrm{MoS}_{2}$ with large amount of edges could also offer enough active sites for HER activities ${ }^{[7,44]}$. The commercial $\mathrm{MoS}_{2}$ nanoflakes liquid-spraying received our 
attention due to the universal of this method enabling easy-fabricating hetero-junction system. Figure 3(a) shows the facile and cost-efficient processes for fabricating the novel hybrid-junction $\mathrm{MoS}_{2} / \mathrm{TiO}_{2}$. All the prepared samples at different processes are noted respectively as $\mathrm{Ti}(\mathbf{A})$, homojunction $\mathrm{TiO}_{2} / \mathrm{Ti}(\mathbf{B})$, pristine $\mathrm{MoS}_{2} / \mathrm{TiO}_{2} / \mathrm{Ti}(\mathbf{C})$ and annealed $\mathrm{MoS}_{2} / \mathrm{TiO}_{2} / \mathrm{Ti}(1 \mathrm{~h} / 2 \mathrm{~h} / 3 \mathrm{~h})(\mathbf{D} / \mathbf{E} / \mathbf{F})$.

Figure 3(b) shows SEM top-view images of the $\mathrm{TiO}_{2}$ (sample B), pristine $\mathrm{MoS}_{2} / \mathrm{TiO}_{2} / \mathrm{Ti}$ (noted as $\mathrm{MoS}_{2} / \mathrm{TiO}_{2}$, sample C) and annealed $\mathrm{MoS}_{2} / \mathrm{TiO}_{2} / \mathrm{Ti}\left(\mathrm{MoS}_{2} / \mathrm{TiO}_{2}\right.$, sample $\mathbf{D}, \mathbf{E}$ and $\left.\mathbf{F}\right)$. The morphology of the materials $\mathrm{TiO}_{2}$ on the surface is shown in Figure 3 (b)-B. The as-received (without thermal treatment) pristine $\mathrm{MoS}_{2}$ shows rough and irregular surface morphology. Upon annealing at $500{ }^{\circ} \mathrm{C}$ in the nitrogen atmosphere, much more dense structure with small pores on the surface is observed in the sample $\mathbf{E}$, mainly due to the thermal treatment which crystalizes the surficial $\mathrm{MoS}_{2}$ microflakes ${ }^{[43]}$. Favouring the specific surface area, these top-porous networks offer more edge sites allowing for HER reactions ${ }^{[45]}$. Furthermore, the thin layer of continuous network structure on the surface provides an accessible tunnel for light penetrating to the inner part of $\mathrm{TiO}_{2}$. After longer annealing time, the undersigned damage to the surface structure could be observed as the potholes in the surface of sample F. Figure S6 show the energy dispersive Xray spectroscopy (EDS) mapping, confirming that the Ti, O, Mo, and S species existed in the multilayered film composites. To verify the thickness of $\mathrm{MoS}_{2}$ and the $\mathrm{MoS}_{2}$ wrapped on the surface of particles, a cross-sectional FESEM analysis was conducted (Figure S7a, b). The FESEM images show distinct wrapping of $\mathrm{MoS}_{2}$, with measured thickness of $1.30 \mathrm{um}\left(\mathrm{MoS}_{2}\right.$ pristine) and $400 \mathrm{~nm}$ $\left(\mathrm{MoS}_{2} 2 \mathrm{~h}\right)$. Element-specific analysis was performed by the dedicated Line-scan EDS along the direction of bottom to surface (Figure 1c), indicating existence of the material of $\mathrm{MoS}_{2}$. The morphology of $\mathrm{MoS}_{2}$ wrapped on the surface of particles was further confirmed by AFM surface topology (Figure S7d). 
Figure 3(c) shows the XRD patterns of five as-prepared hybrid-junction samples. Before spraying $\mathrm{MoS}_{2}$, the peaks of (112) and (204) facets of anatase $\mathrm{TiO}_{2}$ and (111) facet of rutile $\mathrm{TiO}_{2}$ could be observed in Figure 3(c)-B (Anatase PDF 00-021-1272; Rutile PDF 00-021-1276). After annealing, the diffraction characteristic peaks of $\mathrm{TiO}_{2}$ are still observed in the patterns of $\mathrm{MoS}_{2} / \mathrm{TiO}_{2}$ composites with grown crystallite size and strength after the thermal treatment. The peaks centered at $26^{\circ}$ and $28.7^{\circ}$ can be assigned to (101) facet of anatase $\mathrm{TiO}_{2}$ and (110) facet of rutile $\mathrm{TiO}_{2}$ (Anatase PDF 00-021-1272; Rutile PDF 00-021-1276). For $\mathrm{MoS}_{2}$, the detected signals located at $29.5^{\circ}, 44.6^{\circ}$ and $60.5^{\circ}$ are assigned to (004), (006) and (110) $\left(\mathrm{MoS}_{2}\right.$ PDF 01-087-2416) respectively with increased crystallinity along with increasing annealing temperature ${ }^{[46]}$. The crystal phase information on the $\mathrm{TiO}_{2}$ and $\mathrm{MoS}_{2}$ suggests the hetero-junction composite consisting of $\mathrm{MoS}_{2}$ and mixed-phases $\mathrm{TiO}_{2}$ based homo-junction.

The HER activities of $\mathrm{MoS}_{2} / \mathrm{TiO}_{2}$ were measured and compared with that of the $\mathrm{MoS}_{2} / \mathrm{Ti}$. Figure 4a presents photo-current of the obtained dark-current and photo-current (Figure S8(a-c)), in which the $\mathrm{MoS}_{2} / \mathrm{TiO}_{2}\left(500{ }^{\circ} \mathrm{C} 2 \mathrm{~h}\right)$ exhibited higher photo-current during the HER under the light irradiation than the rest, and excellent HER activities with overpotential of $-114 \mathrm{mV}$ at $10 \mathrm{~mA} / \mathrm{cm}^{2}$. The improved overpotential is much lower than that of latest reports, such as $0 \mathrm{D}\left(\mathrm{MoS}_{2}\right) / 2 \mathrm{D}(\mathrm{g}-$ $\mathrm{C}_{3} \mathrm{~N}_{4}$ ) heterojunctions (about $-450 \mathrm{mV}$ at $\left.2 \mathrm{~mA} / \mathrm{cm}^{2}\right)^{[18]}$, a-MoSx @MPA colloidal nanodots (about $-270 \mathrm{mV}$ at $5 \mathrm{~mA} / \mathrm{cm}^{2}$ ) ${ }^{[47]}$ and high-percentage $1 \mathrm{~T}$-phase $\mathrm{MoS}_{2}$ nanodots (about $-180 \mathrm{mV}$ at 10 $\left.\mathrm{mA} / \mathrm{cm}^{2}\right)^{[48]}$. It is even comparable to that of $\mathrm{MoS}_{2}$ with multifunctional active sites (around -100 $\mathrm{mV}$ at $10 \mathrm{~mA} / \mathrm{cm}^{2}$ in $1.0 \mathrm{M}$ aqueous $\left.\mathrm{KOH}\right)^{[49]}$. To examine the role of homo-junction $\mathrm{TiO}_{2}$ in the hetero-junction, the HER activities of $\mathrm{MoS}_{2} / \mathrm{Ti}$ without introducing homo-junction $\mathrm{TiO}_{2}$ was also measured. Figure S8d shows the current density under the dark and light condition during the HER for the $\mathrm{MoS}_{2} / \mathrm{Ti}$. The current density under the light is almost overlapped with the current density 
under the dark, indicating a poor visible light utilization. Thus, the homo-junction $\mathrm{TiO}_{2}$ plays a crucial role on promoting the HER activities of $\mathrm{MoS}_{2} / \mathrm{TiO}_{2}$ after thermal treatment. Figure $4 \mathrm{~b}$ presents the Tafel slope for the $\mathrm{MoS}_{2} / \mathrm{TiO}_{2}\left(500{ }^{\circ} \mathrm{C} 2 \mathrm{~h}\right)$, with a value of $99 \mathrm{mV} /$ decade under the light, much lower than the Tafel slope value $159 \mathrm{mV} /$ decade of $\mathrm{TiO}_{2} / \mathrm{Ti}$ shown in the Figure $2 \mathrm{~d}$. The Tafel slope value is much closer to the Heyrovsky reaction regime (40 $\mathrm{mV} / \mathrm{decade}$ ), therefore the rate-limiting step is changing from the electrochemical adsorption step to the desorption step due to the covered $\mathrm{MoS}_{2}{ }^{[43]}$. In addition, in contrast to the HER activities of singular $\mathrm{TiO}_{2}\left(\mathrm{TiO}_{2} / \mathrm{Ti}\right.$, Figure 2c) and $\mathrm{MoS}_{2}\left(\mathrm{MoS}_{2} / \mathrm{Ti}\right.$, Figure S8d), the hetero-junction of $\mathrm{MoS}_{2} / \mathrm{TiO}_{2}$ exhibits lower overpotential and higher current under the light, suggesting that the hetero-junction interface between the homo-junction $\mathrm{TiO}_{2}$ and $\mathrm{MoS}_{2}$ also contributed to the charge separation and transfer, and then hastened the reaction kinetics.

A long-time stability test for $\mathrm{MoS}_{2} / \mathrm{TiO}_{2}\left(500{ }^{\circ} \mathrm{C} 2 \mathrm{~h}\right)$ was also carried out. Figure $4 \mathrm{c}$ shows the current density measured during an extended electrolysis (15 hours) under the light at constant potential of $-0.3 \mathrm{~V}$ (vs RHE), in which only $5 \%$ current density decay was observed after 12-hours continuous test under the light for the $\mathrm{MoS}_{2} / \mathrm{TiO}_{2}\left(500{ }^{\circ} \mathrm{C} 2 \mathrm{~h}\right)$. For comparison, Figure $4 \mathrm{~d}$ and Figure $4 \mathrm{e}$ present the stability test for both $\mathrm{MoS}_{2} / \mathrm{TiO}_{2}$ without illumination and $\mathrm{MoS}_{2} / \mathrm{Ti}$ with illumination. Almost $30 \%$ current decay was obtained for the $\mathrm{MoS}_{2} / \mathrm{Ti}$ under the light, demonstrating a faster degradation rate than that of $\mathrm{MoS}_{2} / \mathrm{TiO}_{2}$ with/without illumination.

Figure 4f further shows the HER polarization curves before and after 10 hours stability test for the $\mathrm{MoS}_{2} / \mathrm{TiO}_{2}$ with/without the light, in which the current curve under the dark after 10 hours stability measurement displays similar and repeatable features as the initial test before stability test. While a larger deviation in the current was observed under the light condition, indicating that the stability under the light is slightly weaker than that under the dark. We attribute the reason for the 
stability difference between the dark and the light to the photoinduced corrosion process on the edge sites or defect sites of the $\mathrm{MoS}_{2}$ under the light exposure ${ }^{[50]}$, because the faster and stronger reactions happened during the HER under the light. EIS was used to examine the impedance difference. Figure S9 shows the EIS plots, in which a smaller semicircle of the arc line was exhibited for the $\mathrm{MoS}_{2} / \mathrm{TiO}_{2}\left(500{ }^{\circ} \mathrm{C} 2 \mathrm{~h}\right)$ under the light comparing to that under the dark, indicating better interfacial charge-transfer kinetics ${ }^{[43,44]}$. Meanwhile, a concave arc-line representing intense diffusion of ions of the interface between electrolyte and electrode was observed for the $\mathrm{MoS}_{2} / \mathrm{Ti}$ under the light ${ }^{[51,52]}$, suggesting poor charge-transfer property which is in agreement with a weak PEC activities. It should be noted that the high stability of the hybrid-junction of $\mathrm{MoS}_{2} / \mathrm{TiO}_{2}$ is comparable to other reported junctions such as $\mathrm{MoS}_{2} / \mathrm{TiO}_{2}$, nanojunction of (001) Facets $\mathrm{MoS}_{2} /$ Anatase $\mathrm{TiO}_{2}$ (cyclic $\mathrm{H}_{2}$ production for 9 hours) ${ }^{[53]}$, heterojunction of $\mathrm{MoS}_{2} /$ anatase $\mathrm{TiO}_{2}$ (recycle degradation of $\mathrm{MB}$ for 5 hours) ${ }^{[4]}$, and $\mathrm{MoS}_{2} / \mathrm{TiO}_{2}$ Edge-On Heterostructure (12 hours recycling photocatalytic $\mathrm{H}_{2}$ evolution with intermittent evacuation) ${ }^{[26]}$.

\subsection{Discussion}

Figure $\mathrm{S} 10$ a,b shows the UV-Vis absorption spectra of $\mathrm{TiO}_{2}$ and $\mathrm{MoS}_{2}$ respectively, in which the absorption edges of $\mathrm{TiO}_{2}$ and $\mathrm{MoS}_{2}$ were found to be 760 and $990 \mathrm{~nm}$ respectively, corresponding to the direct band gap energy $\left(\mathrm{E}_{\mathrm{g}}\right)$ of $1.63 \mathrm{eV}$ and $1.25 \mathrm{eV}$ derived from BeerLambert law ${ }^{[37]}$ as shown in the Figure S10c. The narrower bandgap energy of homo-junction $\mathrm{TiO}_{2}$ compare with the pure anatase phase $(3.20 \mathrm{eV})$ and rutile phase of $\mathrm{TiO}_{2}(3.03 \mathrm{eV}){ }^{[54]}$ could be attributed to the monolithic homo-junction $\mathrm{TiO}_{2}$. To further understand the band positions, Figure S11 presents the Mott-Schottky plots of the $\mathrm{TiO}_{2}$ and the $\mathrm{MoS}_{2} / \mathrm{TiO}_{2}\left(500{ }^{\circ} \mathrm{C} 2 \mathrm{~h}\right)$ (the inset in Figure S11), in which the positive slopes of Mott-Schottky indicate n-type $\mathrm{TiO}_{2}$ and $\mathrm{MoS}_{2}{ }^{55}$. The labeled flat-band potentials are pointing at the difference between Fermi levels and water- 
oxidation potentials. We assumed that the Fermi levels were close to the conduction band, ignoring the slight difference between the Fermi levels and conduction band which has no effect on the analytical conclusion. Based on this, we propose an energy diagram of charge-carrier generation, separation and migration processes for the hybrid-junction $\mathrm{MoS}_{2} / \mathrm{TiO}_{2}$ on the Ti substrate as illustrated in Figure 5. The detailed Z-scheme mechanism are illustrated in the Figure S12 and explained as follows.

In general, the $\mathrm{MoS}_{2} / \mathrm{TiO}_{2}$ composite shall be working as typical staggered gap (type II) heterojunction under usual double paths of charge transferring ${ }^{[56-59]}$. Guided by the matched bending band between the $\mathrm{MoS}_{2}$ and $\mathrm{TiO}_{2}$, an inner potential difference induced electric field would be created. The electrons from the conduction band (CB) of $\mathrm{MoS}_{2}$ could transfer to the $\mathrm{CB}$ of $\mathrm{TiO}_{2}$; in the meantime, the holes would tend to transfer from the valance band (VB) of $\mathrm{TiO}_{2}$ to the $\mathrm{VB}$ of $\mathrm{MoS}_{2}$. Given the fact that the $\mathrm{CB}$ potential of homo-junction $\mathrm{TiO}_{2}$ is more positive than the standard proton reduction potential of $\mathrm{H}_{2} / \mathrm{H}_{2} \mathrm{O}(0.00 \mathrm{~V}$ Vs NHE), thereby protons cannot be thermodynamically reduced to hydrogen. Similarly, since the VB potential of $\mathrm{MoS}_{2}$ is more negative than that of $\mathrm{O}_{2} / \mathrm{H}_{2} \mathrm{O}(1.23 \mathrm{~V}$ Vs NHE$)$, thus the oxygen evolution reaction is prohibited. However, enhanced HER activities and stability were achieved in the work. Therefore, it is proposed that a direct Z-scheme catalytic mechanism is established. Under the mechanism, the built-in static electric field would guide the electrons from the $\mathrm{CB}$ of homo-junction $\mathrm{TiO}_{2}$ transferring to the interface to combine with the active holes from the $\mathrm{VB}$ of $\mathrm{MoS}_{2}$, thus preventing the electrons in the $\mathrm{CB}$ of homo-junction $\mathrm{TiO}_{2}$ from the strong reducibility and the holes in the $\mathrm{VB}$ of $\mathrm{MoS}_{2}$ from the oxidizability. Thus, an enhanced HER activities could be achieved on the hybridjunction of $\mathrm{MoS}_{2} / \mathrm{TiO}_{2}{ }^{[60]}$ 
For the hetero-junction of $\mathrm{MoS}_{2} / \mathrm{TiO}_{2}$, to further ascertain that the underneath homo-junction $\mathrm{TiO}_{2}$ on the substrate of $\mathrm{Ti}$ still has resonant visible light responsivity during the HER, we applied the linear sweeps $(J-V)$ in anodic direction as shown in Figure S13 under the dark. The oxygen evolution reactions (OER) was observed as gas bubbles in the electrolytes. Note that, once the gas bubbles were generated out of the surface, the surficial $\mathrm{MoS}_{2}$ would delaminate from the surface due to the fact that the OER just taking place on the active sites of inner $\mathrm{TiO}_{2}$. Once irradiated by light, the observed delamination process became much more severe so that deteriorating of $\mathrm{MoS}_{2}$ flakes was observed. The reason could be due to the $\mathrm{TiO}_{2}$ harvesting light energy resulted in the accelerated OER. These findings confirm that the ions and visible light can interacting with the underneath $\mathrm{TiO}_{2}$, possibly owing to surficial porous $\mathrm{MoS}_{2}$. Therefore, the underneath homojunction $\mathrm{TiO}_{2}$ on the substrate of Ti could absorb the visible light and convert the light energy during the catalytic reactions.

The interface between the $\mathrm{TiO}_{2}$ and $\mathrm{Ti}$ in the hetero-junction of $\mathrm{MoS}_{2} / \mathrm{TiO}_{2} / \mathrm{Ti}$ also plays an important effect on the overall charge carriers transfer and separation while restraining the recombination which resulted in the photoluminescence (PL) signal. Thus, PL emission spectra were recorded (Figure S14) to probe the behavior of the interface. Comparing to the PL intensity of $\mathrm{Ti}$ substrate, much weaker intensity of $\mathrm{MoS}_{2} / \mathrm{Ti}, \mathrm{TiO}_{2} / \mathrm{Ti}$ and $\mathrm{MoS}_{2} / \mathrm{TiO}_{2} / \mathrm{Ti}$ were obtained, suggesting the surficial decoration with $\mathrm{MoS}_{2}, \mathrm{TiO}_{2}$, or $\mathrm{MoS}_{2} / \mathrm{TiO}_{2}$ could depress the recombination effectively ${ }^{[61]}$. This confirms the interface is in favor of the charge separation and transfer between the $\mathrm{TiO}_{2}$ and $\mathrm{Ti}$ during the HER under the light.

In brief, the homo-junction on the substrate of Ti and Z-scheme hetero-junction play multiple roles during the whole HER. First, the homo-junction $\mathrm{TiO}_{2}$ with narrow band gap can not only utilize visible light energy to excite the electrons from the VB to $\mathrm{CB}$, but also acquire the hot 
electrons transferred at the interface of quasi-core-shell $\mathrm{TiO}_{2} / \mathrm{Ti}^{[37-40]}$. The homo-junction forms an inter-phase junction to afford the band bending, and then favoring the excited electrons toward the hetero-junction interface. Second, the Z-scheme hetero-junction transports the electrons to the VB of $\mathrm{MoS}_{2}$, where the electrons are then excited to the CB by the sunlight energy, further participating into the HER on the active sites of $\mathrm{MoS}_{2}$. Furthermore, the Z-scheme connection provides excellent protection on the $\mathrm{MoS}_{2}$ through directing the photo-excited holes in the VB of $\mathrm{MoS}_{2}$ toward the hetero-junction interface space meeting with the electrons from the $\mathrm{CB}$ of $\mathrm{TiO}_{2}$, preventing the $\mathrm{MoS}_{2}$ from the photo-excited holes induced corrosion and therefore imparting a higher stability to the system ${ }^{[62]}$. In turn, the upper $\mathrm{MoS}_{2}$ layer also acts as protective material for the underneath $\mathrm{TiO}_{2}$. The low cost of $\mathrm{Ti}$ and $\mathrm{MoS}_{2}$ with simply fabrication processes makes them favorable to demonstrate our hybrid-junction scheme. The optimization for the processes and manipulation should result in better HER performance and enhanced the visible light utilization, like modifying the thickness of $\mathrm{MoS}_{2}{ }^{[63-65]}$.

\section{Conclusions}

Novel hybrid-junction $\mathrm{MoS}_{2} / \mathrm{TiO}_{2} / \mathrm{Ti}$ photocathode was fabricated by a facile process that combines thermal oxidaiton and hand-spraying. This hybrid-junction photocathode under visible light exhibited improved HER activities, in which the overpotential required to obtain $10 \mathrm{~mA} \mathrm{~cm}^{-}$

${ }^{2}$ was reduced to $-114 \mathrm{mV}$, as well as long-term stability was achieved for over more than 12 hours at $-0.3 \mathrm{~V}$ Vs RHE while in comparison the cathode without the introduction of hybrid-junction only persisted about 1 hour under the same conditions. The associated homo-junction and Zscheme hetero-junction were attributed to the enhanced charge carrier dynamics and reduced recombination, therefore improved HER activities under the light. Synthesized by simple one-step 
thermal oxidation process, the homo-junction $\mathrm{TiO}_{2}$ on the substrate of $\mathrm{Ti}$ with plasmonic resonances and charge separation ability is supposed to have more wide range of application capability in sunlight energy-conversion systems. The concept of hybrid-junction provides a costeconomical strategy to regulate the charge carrier separation, transfer and transportation dynamics of photoelectrodes and catalysts that do hold poor characteristic under given working environment for practical solar water splitting.

\section{ACKNOWLEDGEMENT}

The authors would like to acknowledge the support from Norwegian Research Council FRINATEK Programme (231416/F20), China Scholarship Council (CSC, Grant No.201506930002), the Norwegian Micro- and Nano-Fabrication Facility (NorFab, project number 245963/F50), and a STSM Grant from To-BE COST Action (MP 1308) supported by COST (European Cooperation in Science and Technology). We also want to acknowledge the valuable help of Muhammad Tayyib who helped us in the characterization of SEM, EDX and EBSD. 


\section{REFERENCES}

[1] O. Khaselev, A monolithic photovoltaic-photoelectrochemical device for hydrogen production via water splitting, Science, 280 (1998) 425-427.

[2] Y. Tachibana, L. Vayssieres, J.R. Durrant, Artificial photosynthesis for solar watersplitting, Nat. Photonics, 6 (2012) 511-518.

[3] D.M. Fabian, S. Hu, N. Singh, F.A. Houle, T. Hisatomi, K. Domen, F.E. Osterloh, S. Ardo, Particle suspension reactors and materials for solar-driven water splitting, Energy Environ. Sci., 8 (2015) 2825-2850.

[4] A. Landman, H. Dotan, G.E. Shter, M. Wullenkord, A. Houaijia, A. Maljusch, G.S. Grader, A. Rothschild, Photoelectrochemical water splitting in separate oxygen and hydrogen cells, Nat. Mater., 16 (2017) 646-651.

[5] R.M. Navarro, M.C. Alvarez-Galván, J.A. Villoria de la Mano, S.M. Al-Zahrani, J.L.G. Fierro, A framework for visible-light water splitting, Energy Environ. Sci., 3 (2010) 1865.

[6] J.H. Montoya, L.C. Seitz, P. Chakthranont, A. Vojvodic, T.F. Jaramillo, J.K. Norskov, Materials for solar fuels and chemicals, Nat. Mater., 16 (2016) 70-81.

[7] I. Roger, M.A. Shipman, M.D. Symes, Earth-abundant catalysts for electrochemical and photoelectrochemical water splitting, Nat. Rev. Chem., 1 (2017) 0003.

[8] L. Zhou, H. Zhang, H. Sun, S. Liu, M.O. Tade, S. Wang, W. Jin, Recent advances in nonmetal modification of graphitic carbon nitride for photocatalysis: a historic review, Catal. Sci. Technol., 6 (2016) 7002-7023.

[9] F.F. Abdi, L. Han, A.H. Smets, M. Zeman, B. Dam, R. van de Krol, Efficient solar water splitting by enhanced charge separation in a bismuth vanadate-silicon tandem photoelectrode, Nat. Commun., 4 (2013) 2195. Khaselev 
[10] K.T. Fountaine, H.J. Lewerenz, H.A. Atwater, Efficiency limits for photoelectrochemical water-splitting, Nat. Commun., 7 (2016) 13706.

[11] H.M. Chen, C.K. Chen, R.S. Liu, L. Zhang, J. Zhang, D.P. Wilkinson, Nano-architecture and material designs for water splitting photoelectrodes, Chem. Soc. Rev., 41 (2012) $5654-5671$.

[12] S.Y. Reece, J.A. Hamel, K. Sung, T.D. Jarvi, A.J. Esswein, J.J. Pijpers, D.G. Nocera, Wireless solar water splitting using silicon-based semiconductors and earth-abundant catalysts, Science, 334 (2011) 645-648.

[13] J. Luo, J.H. Im, M.T. Mayer, M. Schreier, M.K. Nazeeruddin, N.G. Park, S.D. Tilley, H.J. Fan, M. Gratzel, Water photolysis at $12.3 \%$ efficiency via perovskite photovoltaics and Earth-abundant catalysts, Science, 345 (2014) 1593-1596.

[14] X. Li, J. Yu, J. Low, Y. Fang, J. Xiao, X. Chen, Engineering heterogeneous semiconductors for solar water splitting, J. Mater. Chem. A, 3 (2015) 2485-2534.

[15] L. Yuan, C. Han, M.-Q. Yang, Y.-J. Xu, Photocatalytic water splitting for solar hydrogen generation: fundamentals and recent advancements, Int. Rev. Phys. Chem., 35 (2016) 136.

[16] H. Wang, L. Zhang, Z. Chen, J. Hu, S. Li, Z. Wang, J. Liu, X. Wang, Semiconductor heterojunction photocatalysts: design, construction, and photocatalytic performances, Chem. Soc. Rev., 43 (2014) 5234-5244.

[17] G. Liu, K. Du, S. Haussener, K. Wang, Charge transport in two-photon semiconducting structures for solar fuels, ChemSusChem, 9 (2016) 2878-2904. 
[18] Y. Liu, H. Zhang, J. Ke, J. Zhang, W. Tian, X. Xu, X. Duan, H. Sun, M. O Tade, S. Wang, OD $\left(\mathrm{MoS}_{2}\right) / 2 \mathrm{D}\left(\mathrm{g}-\mathrm{C}_{3} \mathrm{~N}_{4}\right)$ heterojunctions in $\mathrm{Z}$-scheme for enhanced photocatalytic and electrochemical hydrogen evolution, Appl. Catal., B., 228 (2018) 64-74.

[19] R. Abe, Recent progress on photocatalytic and photoelectrochemical water splitting under visible light irradiation, J. Photoch. Photobio. C, 11 (2010) 179-209.

[20] T. Hisatomi, J. Kubota, K. Domen, Recent advances in semiconductors for photocatalytic and photoelectrochemical water splitting, Chem. Soc. Rev., 43 (2014) 7520-7535.

[21] R. Raja, P. Sudhagar, A. Devadoss, C. Terashima, L.K. Shrestha, K. Nakata, R. Jayavel, K. Ariga, A. Fujishima, Pt-free solar driven photoelectrochemical hydrogen fuel generation using $1 \mathrm{~T} \mathrm{MoS}_{2}$ co-catalyst assembled $\mathrm{CdS}$ QDs/ $/ \mathrm{TiO}_{2}$ photoelectrode, Chem Commun (Camb), 51 (2015) 522-525.

[22] Y. Pi, Z. Li, D. Xu, J. Liu, Y. Li, F. Zhang, G. Zhang, W. Peng, X. Fan, 1T-Phase $\mathrm{MoS}_{2}$ Nanosheets on $\mathrm{TiO}_{2}$ nanorod arrays: 3D photoanode with extraordinary catalytic performance, ACS Sustain. Chem. Eng., 5 (2017) 5175-5182.

[23] X. Zhu, X. Liang, X. Fan, X. Su, Fabrication of flower-like $\mathrm{MoS}_{2} / \mathrm{TiO}_{2}$ hybrid as an anode material for lithium ion batteries, RSC Adv., 7 (2017) 38119-38124.

[24] J. Zhang, L. Zhang, W. Yu, F. Jiang, E. Zhang, H. Wang, Z. Kong, J. Xi, Z. Ji, Novel dual heterojunction between $\mathrm{MoS}_{2}$ and anatase $\mathrm{TiO}_{2}$ with coexposed $\{101\}$ and $\{001\}$ facets, J. Am. Ceram. Soc., 100 (2017) 5274-5285.

[25] B. Chen, Y. Meng, J. Sha, C. Zhong, W. Hu, N. Zhao, Preparation of $\mathrm{MoS}_{2} / \mathrm{TiO}_{2}$ based nanocomposites for photocatalysis and rechargeable batteries: progress, challenges, and perspective, Nanoscale, 10 (2017) 34-68. 
[26] H. He, J. Lin, W. Fu, X. Wang, H. Wang, Q. Zeng, Q. Gu, Y. Li, C. Yan, B.K. Tay, C. Xue, X. Hu, S.T. Pantelides, W. Zhou, Z. Liu, $\mathrm{MoS}_{2} / \mathrm{TiO}_{2}$ Edge-on heterostructure for efficient photocatalytic hydrogen evolution, Adv. Energy Mater., 6 (2016) 1600464.

[27] L. Guo, Z. Yang, K. Marcus, Z. Li, B. Luo, L. Zhou, X. Wang, Y. Du, Y. Yang, $\mathrm{MoS}_{2} / \mathrm{TiO}_{2}$ heterostructures as nonmetal plasmonic photocatalysts for highly efficient hydrogen evolution, Energy Environ. Sci., 11 (2018) 106-114.

[28] W.K. Wang, J.J. Chen, X. Zhang, Y.X. Huang, W.W. Li, H.Q. Yu, Self-induced synthesis of phase-junction $\mathrm{TiO}_{2}$ with a tailored rutile to anatase ratio below phase transition temperature, Sci. Rep., 6 (2016) 20491.

[29] A. Li, Z. Wang, H. Yin, S. Wang, P. Yan, B. Huang, X. Wang, R. Li, X. Zong, H. Han, C. Li, Understanding the anatase-rutile phase junction in charge separation and transfer in a $\mathrm{TiO}_{2}$ electrode for photoelectrochemical water splitting, Chem. Sci., 7 (2016) 60766082.

[30] Y. Zhao, N. Hoivik, K. Wang, Recent advance on engineering titanium dioxide nanotubes for photochemical and photoelectrochemical water splitting, Nano Energy, 30 (2016) 728-744.

[31] F.F. Abdi, L. Han, A.H. Smets, M. Zeman, B. Dam, R. van de Krol, Efficient solar water splitting by enhanced charge separation in a bismuth vanadate-silicon tandem photoelectrode, Nat. Commun., 4 (2013) 2195.

[32] N. Wang, M. Liu, H. Tan, J. Liang, Q. Zhang, C. Wei, Y. Zhao, E.H. Sargent, X. Zhang, Compound homojunction: heterojunction reduces bulk and interface recombination in ZnO photoanodes for water splitting, Small, 13 (2017). 
[33] Z. Zhang, Y. Huang, K. Liu, L. Guo, Q. Yuan, B. Dong, Multichannel-improved chargecarrier dynamics in well-designed hetero-nanostructural plasmonic photocatalysts toward highly efficient solar-to-fuels conversion, Adv. Mater., 27 (2015) 5906-5914.

[34] Y.H. Tseng, C.S. Kuo, C.H. Huang, Y.Y. Li, P.W. Chou, C.L. Cheng, M.S. Wong, Visible-light-responsive nano- $\mathrm{TiO}(2)$ with mixed crystal lattice and its photocatalytic activity, Nanotechnology, 17 (2006) 2490-2497.

[35] M.A. Mohamed, W.N. Wan Salleh, J. Jaafar, N. Yusof, Preparation and photocatalytic activity of mixed phase anatase/rutile $\mathrm{TiO}_{2}$ nanoparticles for phenol degradation, Jurnal Teknologi, 70 (2014).

[36] S. Yeniyol, I. Mutlu, Z. He, B. Yuksel, R.J. Boylan, M. Urgen, Z.C. Karabuda, C. Basegmez, J.L. Ricci, Photocatalytical antibacterial activity of mixed-phase $\mathrm{TiO}_{2}$ Nanocomposite thin films against Aggregatibacter actinomycetemcomitans, BioMed research international, 2015 (2015) 705871.

[37] R. Jiang, B. Li, C. Fang, J. Wang, Metal/Semiconductor hybrid nanostructures for plasmon-enhanced applications, Adv. Mater., 26 (2014) 5274-5309.

[38] Y. Pihosh, I. Turkevych, K. Mawatari, N. Fukuda, R. Ohta, M. Tosa, K. Shimamura, E.G. Villora, T. Kitamori, Ubiquitous element approach to plasmonic enhanced photocatalytic water splitting: the case of $\mathrm{Ti} @ \mathrm{TiO}_{2}$ core-shell nanostructure, Nanotechnology, 25 (2014) 315402.

[39] G. Liu, K. Du, J. Xu, G. Chen, M. Gu, C. Yang, K. Wang, H. Jakobsen, Plasmondominated photoelectrodes for solar water splitting, J. Mater. Chem. A, 5 (2017) 42334253. 
[40] S. Tan, A. Argondizzo, J. Ren, L. Liu, J. Zhao, H. Petek, Plasmonic coupling at a metal/semiconductor interface, Nat. Photonics, 11 (2017) 806-812.

[41] M.W. Knight, N.S. King, L. Liu, H.O. Everitt, P. Nordlander, N.J. Halas, Aluminum for plasmonics, ACS nano, 8 (2014) 834-840.

[42] N.T. Thomas, K. Nobe, Kinetics of the hydrogen evolution reaction on titanium, J. Electrochem. Soc., 117 (1970) 622.

[43] D. Kiriya, P. Lobaccaro, H.Y. Nyein, P. Taheri, M. Hettick, H. Shiraki, C.M. Sutter-Fella, P. Zhao, W. Gao, R. Maboudian, J.W. Ager, A. Javey, General thermal texturization process of $\mathrm{MoS}_{2}$ for efficient electrocatalytic hydrogen evolution reaction, Nano Lett., 16 (2016) 4047-4053.

[44] X. Zou, Y. Zhang, Noble metal-free hydrogen evolution catalysts for water splitting, Chem. Soc. Rev., 44 (2015) 5148-5180.

[45] J. Kibsgaard, Z. Chen, B.N. Reinecke, T.F. Jaramillo, Engineering the surface structure of $\mathrm{MoS}_{2}$ to preferentially expose active edge sites for electrocatalysis, Nat. Mater., 11 (2012) 963-969.

[46] X. Hai, W. Zhou, K. Chang, H. Pang, H. Liu, L. Shi, F. Ichihara, J. Ye, Engineering the crystallinity of $\mathrm{MoS}_{2}$ monolayers for highly efficient solar hydrogen production, J. Mater. Chem. A, 5 (2017) 8591-8598.

[47] K. Chang, H. Pang, X. Hai, G. Zhao, H. Zhang, L. Shi, F. Ichihara, J. Ye, Ultra-small freestanding amorphous molybdenum sulfide colloidal nanodots for highly efficient photocatalytic hydrogen evolution reaction, Appl. Catal., B., 232 (2018) 446-453.

[48] C. Tan, Z. Luo, A. Chaturvedi, Y. Cai, Y. Du, Y. Gong, Y. Huang, Z. Lai, X. Zhang, L. Zheng, X. Qi, M.H. Goh, J. Wang, S. Han, X.J. Wu, L. Gu, C. Kloc, H. Zhang, Preparation 
of high-percentage 1T-phase transition metal dichalcogenide nanodots for electrochemical hydrogen evolution, Adv. Mater., 30 (2018).

[49] M.A.R. Anjum, H.Y. Jeong, M.H. Lee, H.S. Shin, J.S. Lee, Efficient hydrogen evolution reaction catalysis in alkaline media by all-in-one $\mathrm{MoS}_{2}$ with multifunctional active sites, Adv. Mater., 30 (2018) e1707105.

[50] E. Parzinger, B. Miller, B. Blaschke, J.A. Garrido, J.W. Ager, A. Holleitner, U. Wurstbauer, Photocatalytic stability of single- and few-layer MoS(2), ACS nano, 9 (2015) 11302-11309.

[51] T. Lopes, L. Andrade, H.A. Ribeiro, A. Mendes, Characterization of photoelectrochemical cells for water splitting by electrochemical impedance spectroscopy, Int. J. Hydrogen Energy, 35 (2010) 11601-11608.

[52] M.I.D.-G.a.R. Gómez, Investigating water splitting with $\mathrm{CaFe}_{2} \mathrm{O}_{4}$ photocathodes by electrochemical impedance spectroscopy, ACS Appl. Mater. Interfaces, 8 (2016) 11.

[53] Y.-J. Yuan, Z.-J. Ye, H.-W. Lu, B. Hu, Y.-H. Li, D.-Q. Chen, J.-S. Zhong, Z.-T. Yu, Z.G. Zou, Constructing anatase $\mathrm{TiO}_{2}$ nanosheets with exposed (001) facets/layered $\mathrm{MoS}_{2}$ two-dimensional nanojunctions for enhanced solar hydrogen generation, ACS Catal., 6 (2015) 532-541.

[54] D.O. Scanlon, C.W. Dunnill, J. Buckeridge, S.A. Shevlin, A.J. Logsdail, S.M. Woodley, C.R. Catlow, M.J. Powell, R.G. Palgrave, I.P. Parkin, G.W. Watson, T.W. Keal, P. Sherwood, A. Walsh, A.A. Sokol, Band alignment of rutile and anatase $\mathrm{TiO}(2)$, Nat. Mater., 12 (2013) 798-801.

[55] N. Baram, Y. Ein-Eli, Electrochemical impedance spectroscopy of porous $\mathrm{TiO}_{2}$ for photocatalytic applications, J. Phys. Chem. C, 114 (2010) 9781-9790. 
[56] L. Cao, R. Wang, D. Wang, X. Li, H. Jia, $\mathrm{MoS}_{2}$-hybridized $\mathrm{TiO}_{2}$ nanosheets with exposed $\{001\}$ facets to enhance the visible-light photocatalytic activity, Mater. Lett., 160 (2015) 286-290.

[57] J. Tao, J. Chai, L. Guan, J. Pan, S. Wang, Effect of interfacial coupling on photocatalytic performance of large scale $\mathrm{MoS}_{2} / \mathrm{TiO}_{2}$ hetero-thin films, Appl. Phys. Lett., 106 (2015) 081602.

[58] D. Wang, Y. Xu, F. Sun, Q. Zhang, P. Wang, X. Wang, Enhanced photocatalytic activity of $\mathrm{TiO}_{2}$ under sunlight by $\mathrm{MoS}_{2}$ nanodots modification, Appl. Surf. Sci., 377 (2016) 221227.

[59] X. Liu, Z. Xing, Y. Zhang, Z. Li, X. Wu, S. Tan, X. Yu, Q. Zhu, W. Zhou, Fabrication of 3D flower-like black $\mathrm{N}-\mathrm{TiO}_{2-\mathrm{x}} @ \mathrm{MoS}_{2}$ for unprecedented-high visible-light-driven photocatalytic performance, Appl. Catal. B: Environ., 201 (2017) 119-127.

[60] Z. Jiang, W. Wan, H. Li, S. Yuan, H. Zhao, P.K. Wong, A hierarchical Z-scheme alpha$\mathrm{FeO}_{3} / \mathrm{g}-\mathrm{C}_{3} \mathrm{~N}_{4}$ hybrid for enhanced photocatalytic $\mathrm{CO}_{2}$ reduction, Adv. Mater., (2018).

[61] X. Yang, H. Huang, B. Jin, J. Luo, X. Zhou, Facile synthesis of $\mathrm{MoS}_{2} / \mathrm{B}-\mathrm{TiO}_{2}$ nanosheets with exposed $\{001\}$ facets and enhanced visible-light-driven photocatalytic $\mathrm{H}_{2}$ production activity, RSC Adv., 6 (2016) 107075-107080.

[62] Y. Yang, Y. Ling, G. Wang, T. Liu, F. Wang, T. Zhai, Y. Tong, Y. Li, Photohole Induced Corrosion of Titanium Dioxide: Mechanism and Solutions, Nano Lett., 15 (2015) 7051 7057.

[63] D. McAteer, Z. Gholamvand, N. McEvoy, A. Harvey, E. O'Malley, G.S. Duesberg, J.N. Coleman, Thickness dependence and percolation scaling of hydrogen production rate in 
$\mathrm{MoS}_{2}$ nanosheet and nanosheet-carbon nanotube composite catalytic electrodes, ACS Nano, 10 (2016) 672-683.

[64] Y. Zhang, H. Li, H. Wang, H. Xie, R. Liu, S.L. Zhang, Z.J. Qiu, Thickness considerations of two-dimensional layered semiconductors for transistor applications, Sci. Rep., 6 (2016) 29615.

[65] A. Sohn, H. Moon, J. Kim, M. Seo, K.-A. Min, S.W. Lee, S. Yoon, S. Hong, D.-W. Kim, Band alignment at $\mathrm{Au} / \mathrm{MoS}_{2}$ contacts: thickness dependence of exfoliated flakes, J. Phys. Chem. C, 121 (2017) 22517-22522. 
Figures (color):
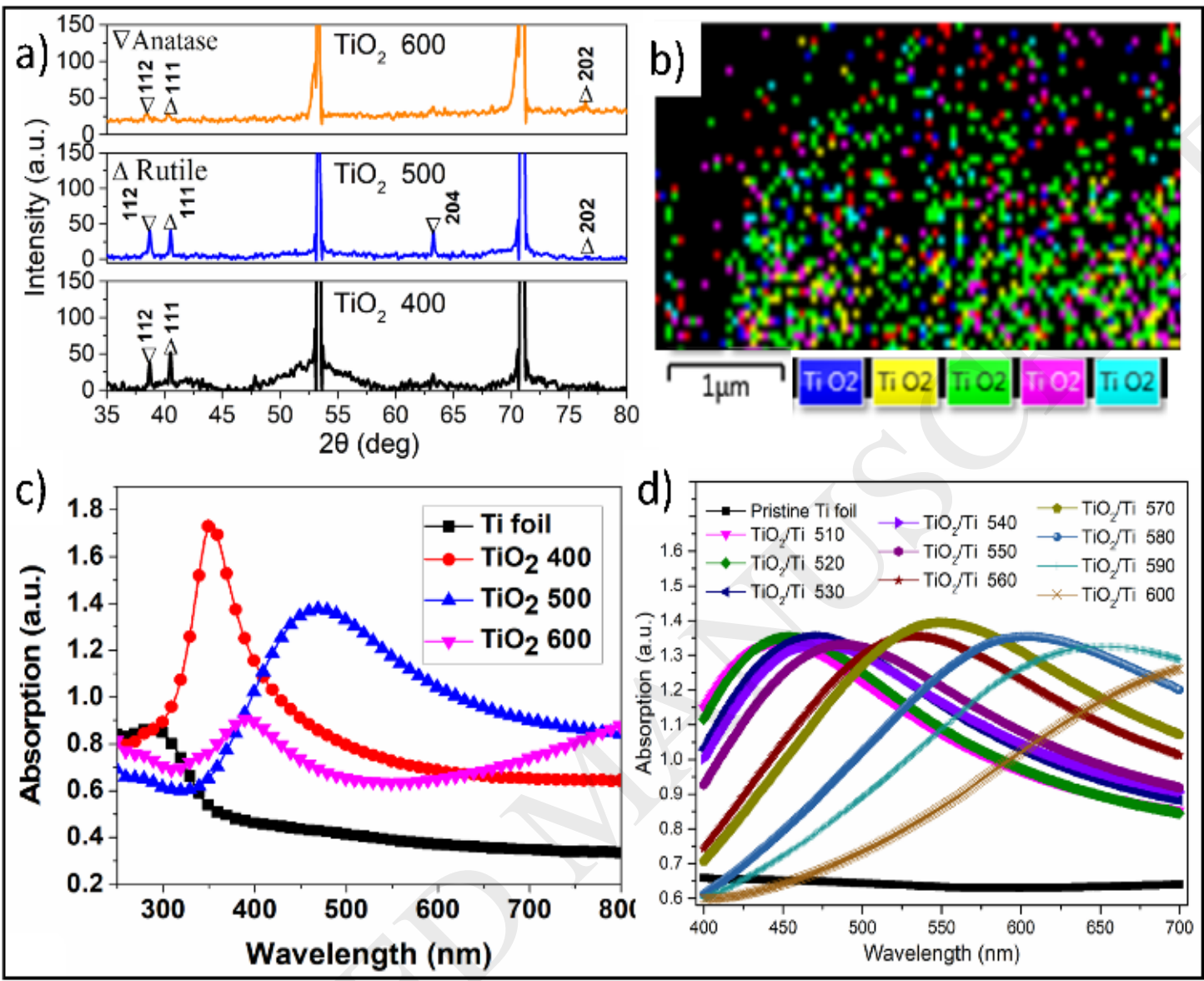

Figure 1. a). XRD patterns of the as-prepared samples. b) Orientation map of mixed-phases $\mathrm{TiO}_{2}$ marked with assorted colors using EBSD microstructural crystallographic technology. More parameters refer to Figure S3 (Table S1, S2 and S3). (c) Ultraviolet-visible (UV-Vis) absorption spectrums of all samples $\mathrm{TiO}_{2} / \mathrm{Ti}$ after 2 hours annealing process at respective 400,500 and $600{ }^{\circ} \mathrm{C}$ (d) UV-Vis absorption spectra of a group of $\mathrm{TiO}_{2} / \mathrm{Ti}$ samples after 2 hours of annealing under varied temperature with distinct visible light absorption bandwidth. 

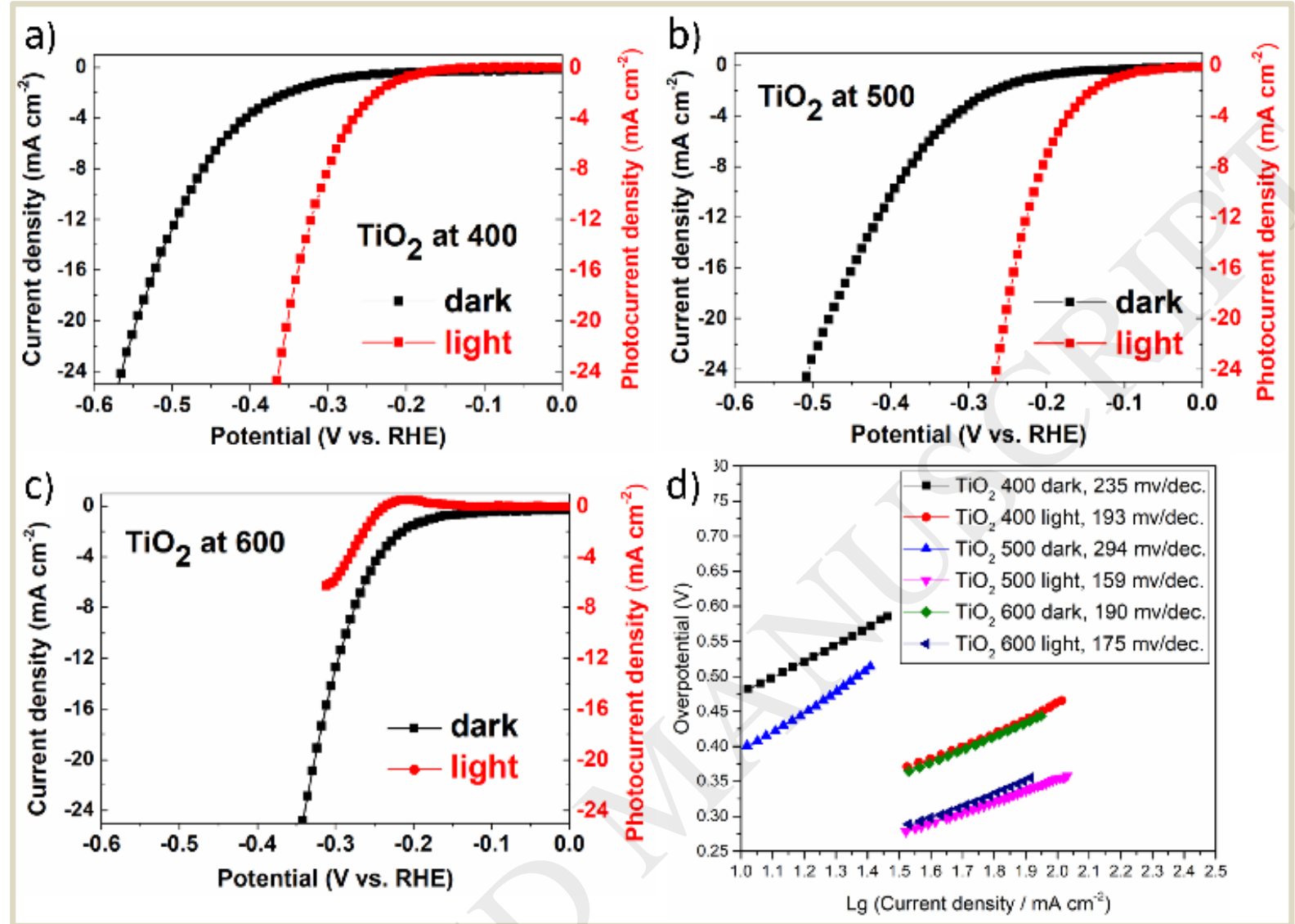

Figure 2. (a-c) Room-temperature $J$ - $V$ curves of the $\mathrm{TiO}_{2} / \mathrm{Ti}$ measured in $0.5 \mathrm{M} \mathrm{H}_{2} \mathrm{SO}_{4}$ under respective dark and light with AM $1.5 \mathrm{G}$ illumination $\left(300 \mathrm{~W} / \mathrm{m}^{2}\right)$. (d) Tafel plots corresponding to the HER polarization curves and related data for the samples. 


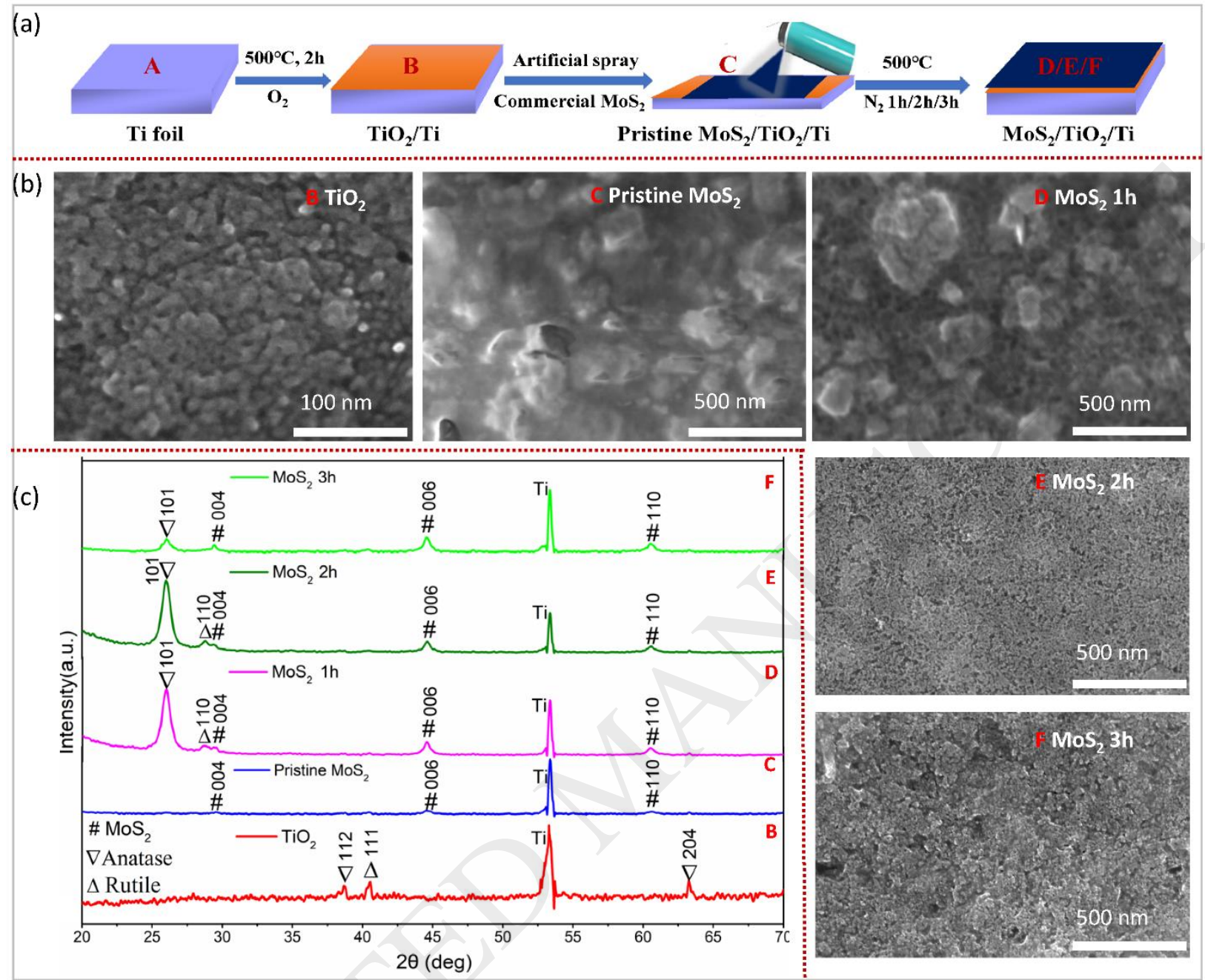

Figure 3. (a). Schematic fabrication processes of all samples. Five kinds of samples involved in the experiments: $\mathrm{Ti}$ foil (sample A), $\mathrm{TiO}_{2} / \mathrm{Ti}$ (sample B), pristine $\mathrm{MoS}_{2} / \mathrm{TiO}_{2} / \mathrm{Ti}$ (sample $\mathbf{C}$ ), and annealed $\mathrm{MoS}_{2} / \mathrm{TiO}_{2} / \mathrm{Ti}$ in nitrogen atmosphere at temperatures of $500{ }^{\circ} \mathrm{C}(1 \mathrm{~h} / 2 \mathrm{~h} / 3 \mathrm{~h})(\mathrm{sample}$ D/E/F). The corresponding SEM images (b) and X-Ray diffraction patterns (c) of the as-received samples. 


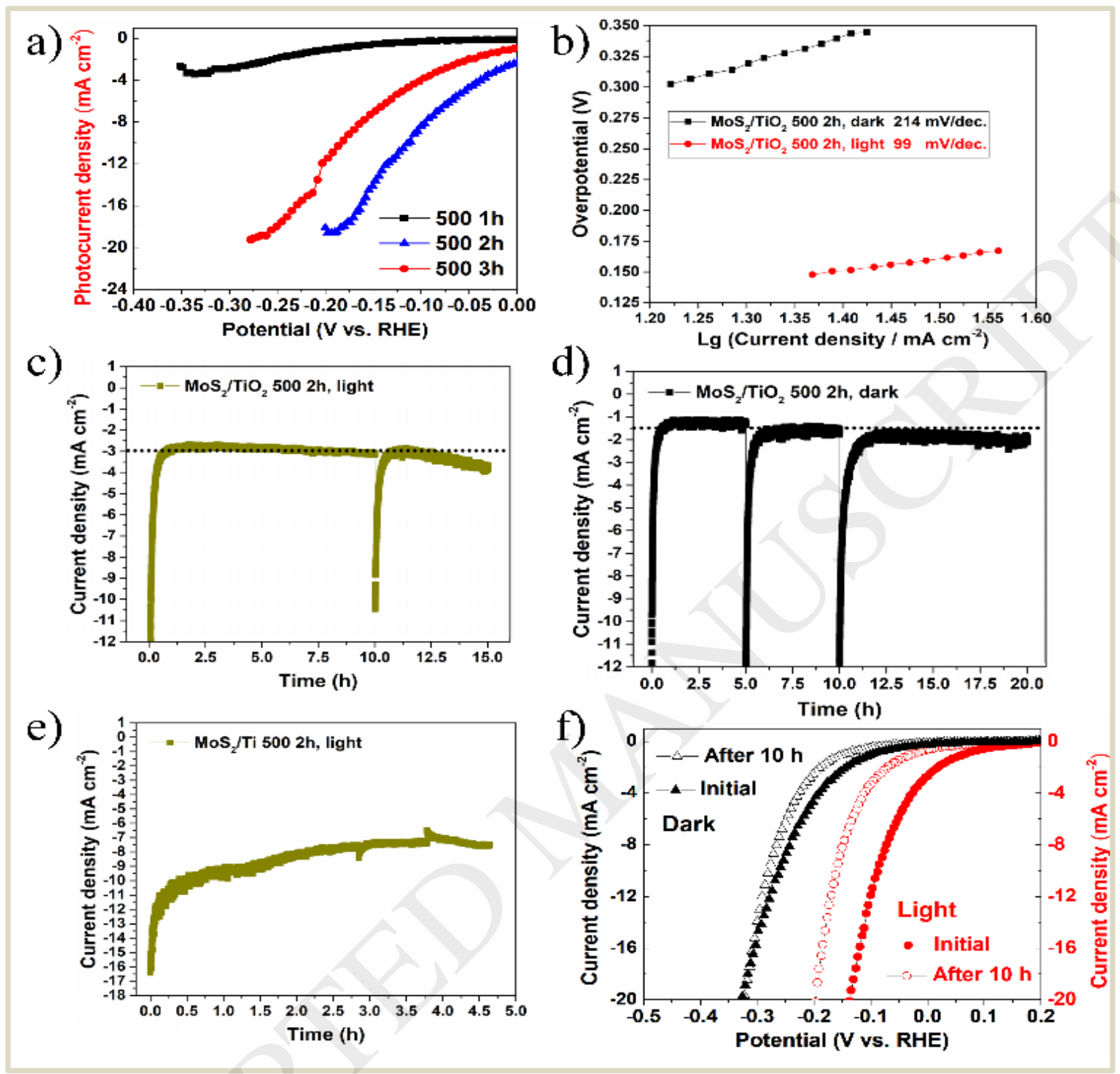

Figure 4. (a) Polarization curves for the composites of $\mathrm{MoS}_{2} / \mathrm{Ti}$, measured in $0.5 \mathrm{M} \mathrm{H}_{2} \mathrm{SO}_{4}$ at a scanning rate of $20 \mathrm{mV} / \mathrm{S}$ under the light. (b) The corresponding Tafel plots and related data for the $\mathrm{MoS}_{2} / \mathrm{Ti}\left(5002 \mathrm{~h}\right.$ ). The long-term stability test for (c) the $\mathrm{MoS}_{2} / \mathrm{Ti}\left(500{ }^{\circ} \mathrm{C} 2 \mathrm{~h}\right.$ ), (d) $\mathrm{MoS}_{2} / \mathrm{TiO}_{2}$ under the dark and (e) $\mathrm{MoS}_{2} / \mathrm{Ti}$ under the light, respectively, during the HER at $-0.3 \mathrm{~V}$ vs RHE for 15 hours. (f) The HER polarization curves of the $\mathrm{MoS}_{2} / \mathrm{Ti}(5002 \mathrm{~h}$ ) measured before and after the 10 hours stability test at $20 \mathrm{mV} / \mathrm{S}$. The figure of 500 in the figures all refers to the temperature of $500{ }^{\circ} \mathrm{C}$ 


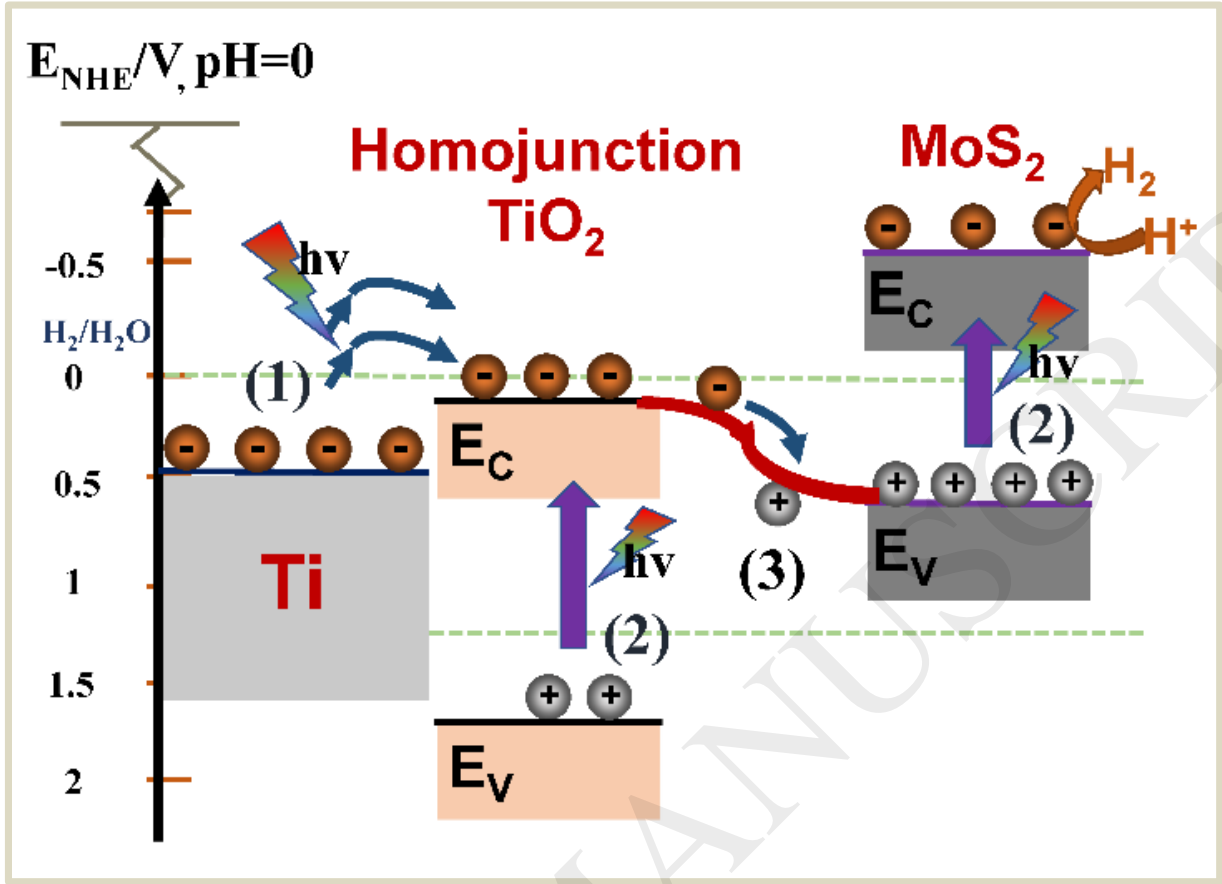

Figure 5. Energy diagram of charge-carrier generation, separation and transportation processes for the hybrid-junction $\mathrm{MoS}_{2} / \mathrm{TiO}_{2}$ on the Ti substrate. (1) Plasmons assisted charge-carrier injection; (2) band-gap enabled excitation of charge-carrier; (3) Z-scheme mechanism of chargecarrier transportation. 